\title{
(6) OPEN ACCESS \\ Dissecting disparity: improvements towards gender parity in leadership and on the podium within the Canadian Orthopaedic Association
}

\author{
Laurie Anne Hiemstra, ${ }^{01,2}$ Trinity Wittman, ${ }^{3}$ Kishore Mulpuri, ${ }^{4}$ Cynthia Vezina, ${ }^{3}$ \\ Sarah Kerslake ${ }^{1}$
}

\begin{abstract}
- Additional material is published online only. To view please visit the journal online (http://dx.doi.org/10.1136/ jisakos-2019-000290)

'Banff Sport Medicine, Banff, Alberta, Canada

${ }^{2}$ Department of Surgery, University of Calgary, Calgary,

Alberta, Canada

${ }^{3}$ Canadian Orthopaedic Association, Westmount, Quebec, Canada

${ }^{4}$ Department of Orthopaedics, University of British Columbia, Vancouver, British Columbia, Canada
\end{abstract}

\section{Correspondence to}

Dr Laurie Anne Hiemstra, Banff Sport Medicine, Banff, AB T1L

1B3, Canada;

hiemstra@banffsportmed.ca

Accepted 6 July 2019

Published Online First

6 September 2019
Check for updates

(C) International Society of Arthroscopy, Knee Surgery and Orthopaedic Sports Medicine 2019. Re-use permitted under CC BY-NC. No commercial reuse. Published by BMJ.

To cite: Hiemstra LA Wittman T, Mulpuri K, et al. J ISAKOS 2019:4:227-232.

\section{ABSTRACT}

Objectives The purpose of this paper was to analyse the 15-year trend of women in leadership roles within the Canadian Orthopaedic Association (COA). This included not only leadership positions at the committee level in the association but also the more visible podium positions in the annual meeting programme: research podium and poster presentations, session moderators, panellists and faculty.

Methods Data on the numbers of male and female members were gathered from COA membership records for the most recent 5 years (2014-2018), as well as for 10 years previous (2009) and 15 years previous (2004). Male and female representation on COA committees, as well as the number of presenters at the annual meeting was calculated. Descriptive data were generated to compare the changes in gender representation over time. Results In Canada, in 2018, 11.2\% of orthopaedic surgeons were female. Within the COA, $17.6 \%$ of the members are female, with active female surgeons comprising $11.6 \%$ of the total membership. The largest increase in representation of women within the COA is in the trainee category which is $25.3 \%$ female. At the 2018 annual meeting, $25 \%$ of the attendees were women, with $22 \%$ of all podium appearances by women. Not including research presentations, women participated as faculty in $11 \%$ of the appearances at the 2018 annual meeting.

Conclusion In conclusion, gender parity is not yet a reality in Canadian orthopaedics; however, the number of females in leadership roles and on the podium is consistent with the current gender diversity within the COA membership. Further efforts will be required to improve gender diversity as well as to encourage female medical students to consider orthopaedics as a specialty. The availability of female role models that are visible on the podium and in leadership positions may be one strategy to encourage the journey toward gender parity.

\section{INTRODUCTION}

Gender imbalance in the academic and professional fields of science and medicine has been the subject of increasing awareness over the last several years. Although there have been improvements in gender parity, with women now adequately represented in medical school classes, academic medicine has yet to achieve equal representation of the sexes. ${ }^{1-4}$ Overall, the surgical specialties have made less progress in narrowing the gender gap than the non-surgical specialties. The increased prevalence of women in medicine and surgery has not translated into an
What are the new findings?

- In Canada, in $2018,11.2 \%$ of practising orthopaedic surgeons were women.

- Within the Canadian Orthopaedic Association (COA), the number of female orthopaedic surgeon members is increasing, with the largest growth in the trainee category.

- The number of females in leadership roles and on the podium at the COA annual meeting is increasing and is consistent with the present gender diversity of the association's membership.

increase in the number of women in academic or professional leadership roles. Currently in the USA, women make up half of medical school classes, $38 \%$ of surgical residents, $22 \%$ of full-time faculty, but only $1 \%$ of surgical chair positions. ${ }^{5}$ Similarly in Canada, although women comprise half of medical school classes, only $27 \%$ of practising surgeons are female. ${ }^{67}$ In Canada's 17 medical schools, there are currently two female deans of medicine, and only three other women have served in this role in the past. ${ }^{8}$ Notably, orthopaedic surgery has been reported to have a significant gender imbalance in combination with the most marginal improvement in gender parity over time..$^{9-12}$ In Canada, in 2018, $11.2 \%$ of orthopaedic surgeons were female, up from $0.9 \%$ in $1968 .^{13}$ In Finland $11 \%$ of orthopaedic surgeons are women, ${ }^{14}$ in the USA $6 \%,{ }^{15}$ in Australia $5 \%,{ }^{16}$ in New Zealand $5.1 \%{ }^{17}$ and in the UK $3 \% .^{18}$ Although these numbers are sobering, the number of women in orthopaedic residency training and fellowship programmes is higher with women now comprising $18.9 \%$ of Canadian postgraduate trainees, up from $16 \%$ in $2008 .{ }^{19}$ In the USA, $14 \%$ of residents are female ${ }^{20}$ and $14 \%$ in New Zealand. ${ }^{17}$ Although promising, these remain the lowest percentages among the surgical specialities. $^{12}$

Multiple barriers have been described to explain the low numbers of women in orthopaedics including limited exposure before and during medical training, a culture of gender bias, a lack of mentors and role models, concerns regarding lifestyle and male chauvinism. ${ }^{12}$ The lack of female role models and mentors has been described as one of the most significant barriers to explain why women choose not to pursue a career in orthopaedic surgery. ${ }^{521}$ In one US study from 2010, 20\% 
of surveyed residency programmes reported having no female department members and $20 \%$ of programmes reported no female residents. ${ }^{22}$ The lack of female role models perpetuates the myth that orthopaedics is not for women, contributes significantly to the 'leaky pipeline effect' in which not enough women are entering the field and the representation of women in leadership roles decreases with career advancement. Although medical training programmes are one vehicle to demonstrate leadership, exposure to female leaders at conferences, courses, meetings, as well as seeing women participate as faculty and presenters on the podium, also increases exposure and visibility. The glass ceiling, a metaphor describing the invisible barrier to women advancing to noticeable leadership positions, ${ }^{23}$ continues to exist in medicine.

The purpose of this paper was to analyse the 15 -year trend of women in leadership roles within the Canadian Orthopaedic Association (COA). This analysis included leadership positions at the committee level within the association, as well as the more visible podium positions in the annual meeting programme: research podium and poster presentations, session moderators, panellists and faculty. The hypothesis for this analysis was that the number of women on the podium at the COA annual meeting would be consistent with the increasing number of female members within the COA, women in the specialty and women attending the annual meeting.

\section{METHODS}

Data on the number of male and female members were gathered from COA membership records from 2004 to 2018. Data were collated annually for the most recent 5 years (2014-2018), as well as for 10 years previous (2009) and 15 years previous (2004). Membership categories included active members, retired members, trainee members (residents and fellows) and allied health (researchers, nurse practitioners, physiotherapists, etc). In addition, male and female representation on COA committees as either members or chairpersons was gathered, as well as data from the archives of the COA annual meetings for the same time periods. The numbers of men and women represented in the following categories were collated: registered attendee, surgeon attendee, moderator, panellist/instructor/faculty, research podium presentation and research poster presentation. Data were entered into Excel (Microsoft Excel 2013) for analysis.

\section{RESULTS}

\section{Membership in COA}

In 2018, there were 1322 full-time orthopaedic surgeons practising in Canada, of which 148 (11.2\%) were female. ${ }^{24}$ Of these surgeons, 994 (75.2\%) were members of the COA. Details on the membership of the COA are presented in table 1 . The overall number of female members of the COA has more than doubled in the last 15 years from 160 to 368, representing an increase in the membership percentage from $9.9 \%$ to $17.6 \%$. The allied health category had the greatest increase in female members, achieving gender parity in 2018 . There has been a slow increase in the number of female surgeon members of the COA since 2004. The number of female surgeon members of the COA in 2018 was 174 of 1504 (11.6\%). This includes those practising full time in Canada, in the USA, internationally and retired surgeons. Including trainees, there are 272/1891 (14.4\%) female surgeon members of the COA.

\section{Leadership within the COA}

Female participation in leadership positions within the COA is represented in table 2 . Committee membership and committee chairperson positions occupied by women have increased over time, in keeping with the overall percentage of female members and surpassing the percentage of female surgeon members of the COA. There has never been a female president of the COA.

\section{Participation at the COA annual meeting}

Female surgeon attendance at the annual meeting is presented in table 3. The largest increase was in the number of female trainee participants, increasing from 14 to 77 (13\%-34\% of total trainees). The attendance numbers for the COA in 2014 were anomalous as this was a combined meeting with the American Orthopaedic Association.

\section{Podium appearances at the COA annual meeting}

The breakdown of male and female podium presenters at the annual meeting is detailed in figure 1 . These data are also presented as percentages in table 4 and distributed by the type of presenter duty. Overall, $25 \%$ of the attendees at the 2018 COA annual meeting were female, and $22 \%$ of podium appearances in all categories were by women. The lowest numbers of women participants are in the instructor and faculty roles. The highest percentages of women are seen in the research presentation sections, both podium and poster. In comparison to the active surgeon participants who are $8.6 \%$ women, the allied health participants for these research presentations are $58 \%$ female. There are typically 3-4 invited guest lecturers at each year's COA annual meeting. There has only been one female guest lecturer during the past 15 years of annual meetings.

A summary comparison of female participation in the COA membership, committees and annual meeting faculty and presenters is presented in figure 2 .

\section{DISCUSSION}

The main finding of this study was that the number of women acquiring leadership roles within the COA has increased over the last 15 years. Female representation at the COA annual Meeting was higher in $2018(22 \%)$ than the overall percentage of female

Table 1 Numbers and percentages of female Canadian Orthopaedic Association members by membership category, 2004-2018

\begin{tabular}{|c|c|c|c|c|c|c|c|}
\hline Year & 2004 & 2009 & 2014 & 2015 & 2016 & 2017 & 2018 \\
\hline Total female members & $160(9.9 \%)$ & $151(9.4 \%)$ & $232(13.3 \%)$ & $286(15.5 \%)$ & $294(15.4 \%)$ & $312(16.6 \%)$ & $368(17.6 \%)$ \\
\hline Canadian actively practising female & $62(7.5 \%)$ & $60(7.5 \%)$ & $97(11.1 \%)$ & $108(12 \%)$ & $131(13.9 \%)$ & $137(14.5 \%)$ & $150(15.1 \%)$ \\
\hline US/International actively practising female & $15(7.8 \%)$ & $14(7.2 \%)$ & $15(8.4 \%)$ & $17(9.8 \%)$ & $15(9.1 \%)$ & $16(10.4 \%)$ & $19(11.1 \%)$ \\
\hline Trainee female & $69(20.8 \%)$ & $64(19.9 \%)$ & $76(25.5 \%)$ & $88(26.8 \%)$ & $75(24.7 \%)$ & $63(25.4 \%)$ & $98(25.3 \%)$ \\
\hline Retired female & $3(1.2 \%)$ & $2(0.8 \%)$ & $2(0.8 \%)$ & $9(3 \%)$ & $5(1.5 \%)$ & $8(2.4 \%)$ & $5(1.5 \%)$ \\
\hline Allied health female & $11(20.8 \%)$ & $11(20.8)$ & $42(35.9 \%)$ & $64(43 \%)$ & $68(39.3)$ & $88(43.8 \%)$ & $96(48 \%)$ \\
\hline Total membership & 1623 & 1611 & 1741 & 1848 & 1911 & 1885 & 2091 \\
\hline
\end{tabular}


Table 2 Leadership positions held by females within the Canadian Orthopaedic Association

\begin{tabular}{llllllll}
\hline YEAR & 2004 & 2009 & 2014 & 2015 & 2016 & 2017 & 2018 \\
\hline Female committee positions & $2 / 119(2 \%)$ & $9 / 115(8 \%)$ & $12 / 116(10 \%)$ & $20 / 154(13 \%)$ & $21 / 162(13 \%)$ & $17 / 150(11 \%)$ & $24 / 144(17 \%)$ \\
Female committee chairs & $0 / 12$ & $0 / 13$ & $2 / 15(13 \%)$ & $0 / 16$ & $2 / 15(13 \%)$ & $2 / 14(14 \%)$ & $2 / 13(15 \%)$ \\
\hline
\end{tabular}

Table 3 Surgeon attendance at the COA annual meeting

\begin{tabular}{llllllll}
\hline Year & 2004 & 2009 & 2014 & 2015 & 2016 & 2017 & 2018 \\
\hline Total surgeon attendees (male and female) & 476 & 423 & 1354 & 617 & 781 & 663 & 706 \\
\hline Total female surgeons & $39(8.2 \%)$ & $55(13 \%)$ & $182(13.4 \%)$ & $92(14.9 \%)$ & $143(18.3 \%)$ & $112(16.9 \%)$ & $142(20.1 \%)$ \\
Actively practising female surgeons & $25(5.3 \%)$ & $28(6.6 \%)$ & $96(7.1 \%)$ & $42(6.8 \%)$ & $78(10 \%)$ & $68(10.3 \%)$ & $64(9.1 \%)$ \\
Retired female surgeons & 0 & 0 & 1 & 1 & 3 & 1 & $1(0.14 \%)$ \\
\hline Trainee female surgeons & $14(2.9 \%)$ & $27(6.4 \%)$ & $85(6.3 \%)$ & $49(7.9 \%)$ & $62(7.9 \%)$ & $43(6.5 \%)$ & $77(10.9 \%)$ \\
\hline
\end{tabular}

members of the COA (18\%), and this number approached the percentage of female attendees at the annual meeting (25\%). The percentage of female surgeon attendees (20\%) was greater than the percentage of female surgeon members of the COA (14.4\%). The highest percentage of female surgeon attendees was in the trainee category (34\%). Committee participation and committee chair appointments were in keeping with the female membership of the COA.

For 2018, the data demonstrated that there was no apparent gender discrepancy between the audience and the podium presenters at the COA annual meeting. Although the increased visibility of women on the podium at the COA annual meeting may have enhanced the status of women in the specialty, the majority of increases were specific to the allied health and trainee categories, rather than the actively practising surgeon category. Annual meeting instructors and faculty were predominately practising orthopaedic surgeons and were composed of $12 \%$ women, consistent with the active female surgeon membership of the COA. The low percentage of women in annual meeting faculty and leadership roles in the COA indicates that there is room for improvement in providing opportunities for, and facilitation of, women in orthopaedic surgery. The presence of greater numbers of female leaders at orthopaedic surgery meetings provides an environment for generating collaboration, improving recognition and respect for female surgeons, ${ }^{25}$ and access to opportunity for career advancement. Importantly, this metric is measurable, enabling researchers and professional organisations to track improvements in gender diversity over time and to enable comparisons between regions, countries and continents.

Many barriers have been identified for the admission and advancement of women in orthopaedics. These barriers affect the efforts to attract women into orthopaedics and contribute to the glass ceiling, which limits the advancement of women into leadership roles within the specialty. Lack of exposure to orthopaedics and musculoskeletal medicine during training, ${ }^{126-29}$ the negative bias against women in orthopaedics, both implicit and overt, ${ }^{30-32}$ and the lack of female role models ${ }^{9} 3033$ have all been implicated in contributing to this gender disparity.

Medical schools with a dedicated musculoskeletal curriculum demonstrated a $75 \%$ increase in the number of women applying for orthopaedic residency. ${ }^{27}$ Exposure to the specialty may dispel some of the misconceptions concerning the physical strength required to perform orthopaedic surgery and the lifestyle and family issues related to surgical specialties. Programmes such as the Perry Initiative and Nth dimensions have demonstrated that early exposure to orthopaedics positively influences women to choose orthopaedic surgery as their surgical specialty. ${ }^{2635}$ These

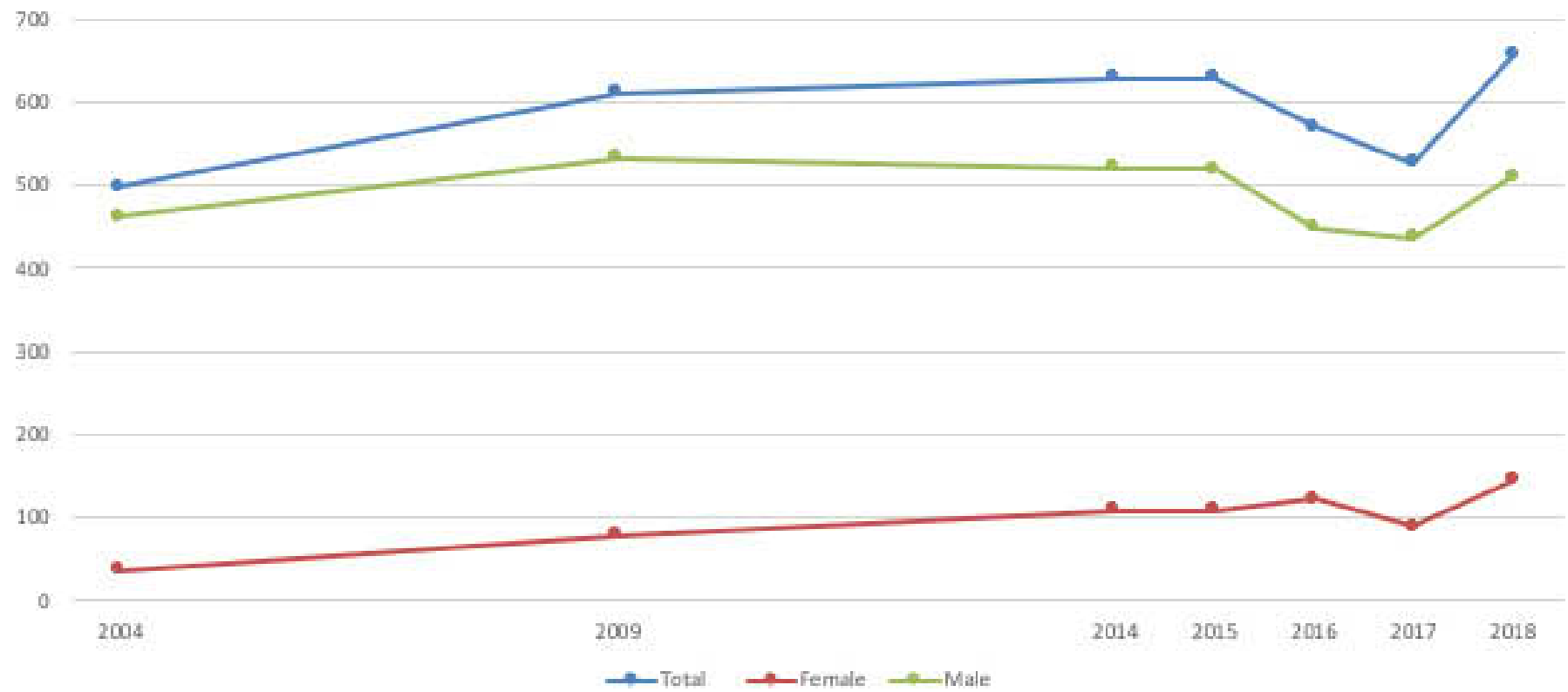

Figure 1 Number of presenters and faculty at the Canadian Orthopaedic Association annual meeting by gender. 
Table 4 The percentage of female participation in the Canadian Orthopaedic Association annual meeting for each type of presenter duty

\begin{tabular}{|c|c|c|c|c|c|c|c|}
\hline & 2004 & 2009 & 2014 & 2015 & 2016 & 2017 & 2018 \\
\hline Attendance & $20 \%$ & $20 \%$ & $18 \%$ & $22 \%$ & $24 \%$ & $24 \%$ & $25 \%$ \\
\hline All presenters and faculty & $7 \%$ & $13 \%$ & $17 \%$ & $17 \%$ & $21 \%$ & $17 \%$ & $22 \%$ \\
\hline Research podiumpresenter & $15 \%$ & $16 \%$ & $19 \%$ & $23 \%$ & $26 \%$ & $24 \%$ & $25 \%$ \\
\hline Research posterpresenter & $12 \%$ & $15 \%$ & $20 \%$ & $16 \%$ & $21 \%$ & $21 \%$ & $32 \%$ \\
\hline Panellist/instructor/faculty & $1 \%$ & $10 \%$ & $9 \%$ & $11 \%$ & $13 \%$ & $9 \%$ & $12 \%$ \\
\hline
\end{tabular}

programmes have shown that exposure to the realities of orthopaedic surgery served to improve the negative perceptions that medical students had of orthopaedic surgery as a profession ${ }^{26}$ and resulted in improved female applications to orthopaedic residency with an odds ratio of up to $66 .^{35}$

Implicit or unconscious bias, encompasses the attitudes and perceptions that people have towards other people, and exists outside of conscious knowledge. Implicit bias negatively affects all aspects of women's orthopaedic surgery careers and has been implicated in the challenge of attracting women to orthopaedic surgery, optimising career development for women, gender pay inequities, and the lack of leadership opportunities for women. Carnes et al eloquently summarised this concept as follows, 'considerable evidence suggests that the failure of academic medical centres to advance women is in large measure owing to the systematic disadvantage women experience daily and at each evaluation point in an academic career' ${ }^{23}$ Female physicians are five times more likely than men to experience barriers to career advancement. ${ }^{36}$ Overall, women in the science, technology and medicine specialties were less likely to be published, ${ }^{37}$ receive less grant money, ${ }^{38} 39$ receive less research start-up funds, ${ }^{40}$ were less likely to be on journal editorial boards ${ }^{41}$ and were less likely to receive physician recognition awards. ${ }^{42}$ In one survey of 152 highly successful orthopaedic surgeons in leadership roles (department chairs, journal editors, journal editorial board and current or past presidents of major orthopaedic associations), only five $(3.3 \%)$ were women. ${ }^{43}$

The lack of female mentors and role models is often cited as a reason why women do not choose to pursue orthopaedic surgery. ${ }^{5}$ This paucity of females may also contribute to the glass ceiling in academic orthopaedics where there are very few women in leadership roles. ${ }^{22} 3343$ Mentoring and role modelling are related but are not the same. Mentoring is a long-term commitment to teach, guide and promote the professional and personal life of a mentee. ${ }^{21}$ Role modelling is a process whereby a positive example is set that will influence the recipient. ${ }^{21}$ Both role modelling and mentoring are integral to improving the gender gap in orthopaedic surgery. Studies show that there is a general lack of female role models and mentors in medicine ${ }^{344}$ and that mentoring is key to encouraging women to pursue orthopaedics. ${ }^{102133}$ Van Heest and Agel demonstrated that the presence of women in an orthopaedic training programme as well as exposure to female faculty were the most important factors in attracting more women into the programme. ${ }^{10}$ A less explored facet of role modelling is the visible leadership positions on the podium at meetings and conferences, including participation as faculty, presenters and moderators. The participation by female surgeons at all career stages in meetings and conferences will provide role models and mentors which may influence the number of women choosing to pursue and complete their orthopaedic training.

Research on the role of women on the podium has been pursued in the field of basic science. Casadevall et al reported that women were under-represented on the podium at past American Society of Microbiology meetings. ${ }^{45}$ However, when a woman was on the speaker selection committee, there was a $72 \%$ increase in female participation and $70 \%$ lower likelihood of an all-male panel. By presenting this data to the programme committee, the researchers demonstrated that the number of women on the podium increased but there were just as many all-male panels. Following this finding, the programme committee was mandated to avoid all-male speaker panels and the meeting achieved gender parity with this intervention. ${ }^{46}$ The authors concluded that awareness of the gender issue prompted the change and suggested three strategies to improve gender balance: (1) enhance awareness by providing data from previous meetings; (2) include women on the committee that selects the meeting presenters and (3) provide instructions to avoid all one-gender panels. ${ }^{46}$

Aiming for gender parity in leadership positions is important for a range of reasons. Diversity encourages innovation, promotes the consideration of alternative points of view and provokes thought. In business, gender-diverse groups perform better, have increased productivity and generate larger profits. ${ }^{47}$ Within healthcare, diversity among workers is imperative for the delivery of quality patient care ${ }^{48}$ and for providing a greater understanding of the patients that we treat. Perhaps most importantly, however, discrimination on the basis of gender is unethical

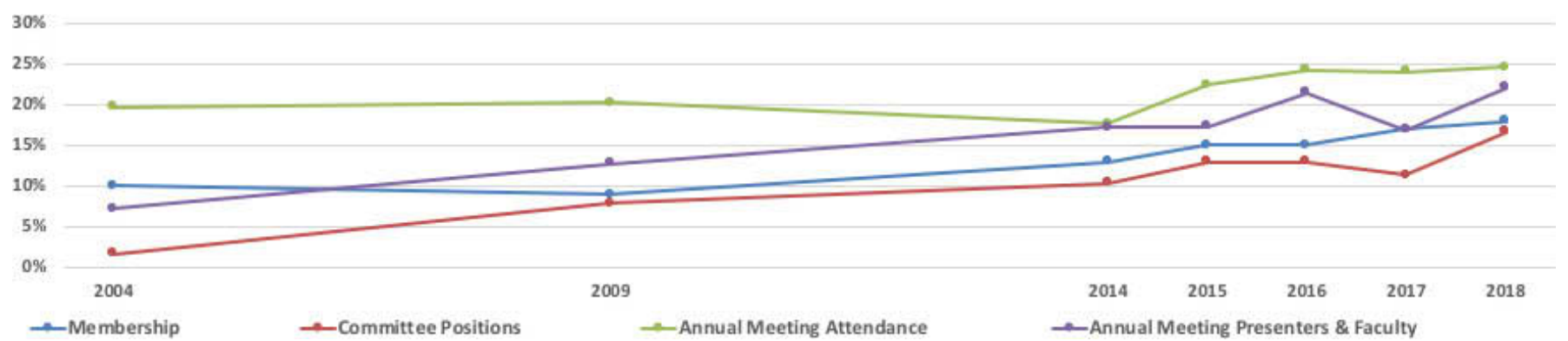

Figure 2 Overall percentage of female participation in the Canadian Orthopaedic Association 2004-2018. 
and unprofessional. The Be Ethical campaign states 'the equitable treatment of women in medicine is an ethical imperative'. ${ }^{49}$ Westring describes an integrated framework for gender equity which includes four interrelated aspects of equal access to resources and opportunities, minimising unconscious gender bias, enhancing work-life balance and leadership engagement. ${ }^{50}$ Online supplementary appendix 1 provides practical strategies for the application of these principles to orthopaedic surgery.

'If gender equality is the end, gender equity is the means'. ${ }^{51}$ Gender equity requires the equality of opportunity for women by making certain that opportunity is not limited on the basis of gender. The current reality is that women physicians bear the majority of the responsibility for childcare and domestic duties, ${ }^{52}$ which creates barriers for women when it comes to excelling in their careers, and assuming leadership roles. Schedules that are inflexible, limited access to on-site childcare, rounds and meetings that occur during peak family times, and the structure of travelling fellowships, all interfere with the ability of women to compete on an equal basis with men. Efforts should be focused on eliminating these biases, so that women have equality of opportunity to advance their careers. The recruitment of more women into orthopaedics will improve gender diversity and reduce implicit bias. Providing equitable opportunities in hiring will mitigate gender disparity, and the encouragement and promotion of women into positions of leadership will assist in eliminating the glass ceiling. Representation of women on the podium at conferences and in visible leadership roles within organisations is vital to encouraging and influencing women to select orthopaedics as their surgical specialty. ${ }^{9}$ Women in leadership roles will also reinforce the notion that success is not gender dependent.

This is a descriptive study and will have the requisite limitations. This includes the inability to gather detailed data on the number of surgeons in Canada who are not members of the COA. Also, the attendance numbers for the COA annual meeting in 2014 were anomalous as this was a combined meeting with the American Orthopaedic Association. All sessions during this meeting were combined with members of both organisations attending; however, as the percentage data for women on the podium was consistent, it was assessed in the same manner as the other years included in this study. Another limitation is that this study does not separately consider individuals who do not identify as either male or female. Finally, comparative data to other countries is scarce and as such is not well documented. Clearly, further work needs to be undertaken to improve the understanding of gender parity in orthopaedic surgery across the globe.

In conclusion, gender parity is not yet a reality within the $\mathrm{COA}$; however, the number of females in leadership roles and on the podium is consistent with the gender diversity of the membership. Further efforts will be required to improve gender diversity as well as to encourage female medical students to consider orthopaedics as a specialty. The availability of female role models that are visible on the podium and in leadership positions may be one strategy to encourage the journey towards gender parity.

Acknowledgements We are grateful to Elizabeth Chatham and Lexie Bilhete, for their assistance in gathering data, as well as to the COA Executive Committee for their collaboration in enabling the publication of this research.

Contributors LAH, TW, CV and SK were involved in study design and data analysis. LAH was the primary author of the manuscript. TW, KM, CV and SK were involved in editing of the manuscript.
Funding The authors have not declared a specific grant for this research from any funding agency in the public, commercial or not-for-profit sectors.

Competing interests $\mathrm{LAH}$ and $\mathrm{KM}$ are on the executive and board of the Canadian Orthopaedic Association. CV and TW are employees of the Canadian Orthopaedic Association. SK has nothing to declare.

Patient consent for publication Not required.

Provenance and peer review Not commissioned; externally peer reviewed.

Data availability statement All data relevant to the study are included in the article or uploaded as supplementary information.

Open access This is an open access article distributed in accordance with the Creative Commons Attribution Non Commercial (CC BY-NC 4.0) license, which permits others to distribute, remix, adapt, build upon this work non-commercially, and license their derivative works on different terms, provided the original work is properly cited, an indication of whether changes were made, and the use is noncommercial. See: http://creativecommons.org/licenses/by-nc/4.0/.

\section{REFERENCES}

1 Tesch BJ, Wood HM, Helwig AL, et al. Promotion of women physicians in academic medicine. glass ceiling or sticky floor? JAMA 1995;273:1022-5.

2 Bickel J, Wara D, Atkinson BF, et al. Increasing women's leadership in academic medicine: report of the AAMC project implementation Committee. Acad Med 2002;77:1043-61.

3 Kass RB, Souba WW, Thorndyke LE. Challenges confronting female surgical leaders: overcoming the barriers. J Surg Res 2006;132:179-87.

4 Wright AL, Schwindt LA, Bassford TL, et al. Gender differences in academic advancement: patterns, causes, and potential solutions in one US College of medicine. Acad Med 2003;78:500-8.

5 Seemann NM, Webster F, Holden HA, et al. Women in academic surgery: why is the playing field still not level? Am I Surg 2016:211:343-9.

6 Acai A, Steyn C, Reid SE, et al. A solution to gender inequity in surgery? Better caregiving policies. Can J Surg 2018;61:6-7.

7 Supply, distribution and migration of physicians in Canada, 2016: methodological notes, 2017. Available: https://www.cihi.ca: [Accessed Canadian Institute for Health Information].

8 CMA. Addressing Gender Equity and Diveristy in Canada's Medical Profession: A Review. Canadian Medical Association, 2018.

9 Lewis VO, Scherl SA, O'Connor MI. Women in orthopaedics - way behind the number curve. J Bone Joint Surg Am 2012:94:e30-1.

10 Van Heest AE, Agel J. The uneven distribution of women in orthopaedic surgery resident training programs in the United States. J Bone Joint Surg Am 2012;94:e9-18

11 Blakemore LC, Hall JM, Biermann JS. Women in surgical residency training programs. J Bone Joint Surg Am 2003;85:2477-80.

12 Miller EK, LaPorte DM. Barriers to women entering the field of orthopedic surgery. Orthopedics 2015;38:530-3.

13 Fruehauf TCK. Toward gender parity in Canadian medicine: OMA online visualizations illustrate marked increase in practicing female physicians across Canada over five decades. Ontario Medical Review 2018;85:15-20.

14 Soy. Suomen Ortopediyhdistys, 2019. Available: http://www.soy.fi/index.php?page= 1069\&lang $=1$

15 Brotherton SE, Etzel SI. Graduate medical education, 2011-2012. JAMA 2012;308:2264-79.

16 AOA. Diversity in healthcare: Australian orthopaedic association, 2017. Available: https://www.aoa.org.au/for-patients/articles-and-galleries/article-diversity-inhealthcare

17 NZOA. New Zealand orthopaedic association, 2019.

18 Bucknall V, Pynsent PB. Sex and the orthopaedic surgeon: a survey of patient, medical student and male orthopaedic surgeon attitudes towards female orthopaedic surgeons. Surgeon 2009;7:89-95.

19 Statistics T-i-CME. Canadian medical education statistics 2018. Ottawa: Association of Faculties of Medicine of Canada, 2019: 208.

20 Joliff LLJ, Coakley E, Sloane RA. Women in US Academic Medicine and Science: statistics and benchmarking report 2011-2012 Assocation of American Medical Colleges, 2012. Available: https://www.aamc.org/download/415556/data/20112012wimsstatsreport.pdf

21 Mulcahey MK, Waterman BR, Hart R, et al. The role of mentoring in the development of successful orthopaedic surgeons. J Am Acad Orthop Surg 2018:26:463-71.

22 Nguyen L, Amin NH, Vail TP, Petrobon TP, R; Shah A, et al. Editorial: a paucity of women among residents, faculty, and chairpersons in orthopaedic surgery. Clin Orthop Relat Res 2010;468:1746-8.

23 Carnes M, Morrissey C, Geller SE. Women's health and women's leadership in academic medicine: hitting the same glass ceiling? J Womens Health 2008;17:1453-62. 
Original article

24 Wittman TOK, Schemitsch EH, Matache B, et al. Resident morale is cautiously reasonable while graduate Underemplyment remains at the forefront of $\mathrm{CoA}$ efforts. Canadian Orthopaedic Association Bulletin 2018:38-44.

25 Martin JL. Ten simple rules to achieve conference SPEAKER gender balance. PLoS Comput Biol 2014;10:e1003903.

26 Lattanza LL, Meszaros-Dearolf L, O'Connor Ml, et al. The Perry initiative's medical student outreach program recruits women into orthopaedic residency. Clin Orthop Relat Res 2016;474:1962-6.

27 Bernstein J, DiCaprio MR, Mehta S. The relationship between required medical school instruction in musculoskeletal medicine and application rates to orthopaedic surgery residency programs. J Bone Joint Surg Am 2004;86:2335-8.

28 Hill JF, Yule A, Zurakowski D, et al. Residents' perceptions of sex diversity in orthopaedic surgery. J Bone Joint Surg Am 2013;95:e144-1-6.

29 Freedman KB, Bernstein J. Educational deficiencies in musculoskeletal medicine. J Bone Joint Surg Am 2002;84:604-8.

30 Zhuge Y, Kaufman J, Simeone DM, et al. Is there still a glass ceiling for women in academic surgery? Ann Surg 2011;253:637-43.

31 Templeton K, Wood VJ, Haynes R. Women and minorities in orthopaedic residency programs. J Am Acad Orthop Surg 2007;15 Suppl 1(Suppl 1):S37-S41.

32 Saalwachter AR, Freischlag JA, Sawyer RG, et al. The training needs and priorities of male and female surgeons and their trainees. J Am Coll Surg 2005;201:199-205.

33 Tosi LL, Mankin HJ. Ensuring the success of women in academic orthopaedics. Clin Orthop Relat Res 1998;356:254-63.

34 Yedidia MJ, Bickel J. Why aren't there more women leaders in academic medicine? The views of clinical department chairs. Acad Med 2001;76:453-65.

35 Mason BS, Ross W, Ortega G, et al. Can a strategic pipeline initiative increase the number of women and underrepresented minorities in orthopaedic surgery? Clin Orthop Relat Res 2016;474:1979-85.

36 Coombs AAT, King RK. Workplace discrimination: experiences of practicing physicians. J Natl Med Assoc 2005;97:467-77.

37 Jagsi R, Griffith KA, Stewart A, et al. Gender differences in the salaries of physician researchers. JAMA 2012;307:2410-7.
38 Kaatz A, Lee Y-G, Potvien A, et al. Analysis of National Institutes of Health R01 application critiques, impact, and criteria scores: does the sex of the principal investigator make a difference? Acad Med 2016;91:1080-8.

39 Tamblyn R, Girard N, Qian CJ, et al. Assessment of potential bias in research grant peer review in Canada. CMAJ 2018;190:E489-E499.

40 Oliveira DFM, Ma Y, Woodruff TK, et al. Comparison of national Institutes of health grant amounts to first-time male and female principal Investigators. JAMA 2019;321:898-900.

41 Amrein K, Langmann A, Fahrleitner-Pammer A, et al. Women underrepresented on editorial boards of 60 major medical journals. Gend Med 2011;8:378-87.

42 Silver JK, Slocum CS, Bank AM, et al. Where are the women? the underrepresentation of women physicians among recognition Award recipients from medical specialty societies. Pm R 2017;9:804-15.

43 Klein G, Hussain N, Sprague $\mathrm{S}$, et al. Characteristics of highly successful orthopedic surgeons: a survey of orthopedic chairs and editors. Can J Surg 2013;56:192-8.

44 Colletti LM, Mulholland MW, Sonnad SS. Perceived obstacles to career success for women in academic surgery. Arch Surg 2000;135:972-7.

45 Casadevall A, Handelsman J. The presence of female conveners correlates with a higher proportion of female speakers at scientific symposia. MBio 2014;5:e00846-13.

46 Casadevall A. Achieving SPEAKER gender equity at the American Society for microbiology general meeting. MBio 2015;6:e01146.

47 McKinsey. Women matter: time to accelerate. ten years of insights into gender diversity, 2017. Available: https://www.mckinsey.com/featured-insights/genderequality/women-matter-ten-years-of-insights-on-gender-diversity

48 Cohen KL. Racial and ethnic disparities in health care. Ann Intern Med 2005;142:153

49 Campaign BE. \# Be Ethical - A Call to Helathcare Leaders: Ending Gender Workforce Disparities is an Ethical Imperative. v.3 ed 2017.

50 Westring AF, Speck RM, Sammel MD, et al. A culture conducive to women's academic success: development of a measure. Acad Med 2012;87:1622-31.

51 Roy K. Why we need gender equity now: ForbesWoman - Ellevate, 2019. Available: https://www.forbes.com/sites/ellevate/2017/09/14/why-we-need-gender-equity-now/

52 Lyu HG, Davids JS, Scully RE, et al. Association of domestic responsibilities with career satisfaction for physician mothers in procedural vs nonprocedural fields. JAMA Surg 2019. doi:10.1001/jamasurg.2019.0529 